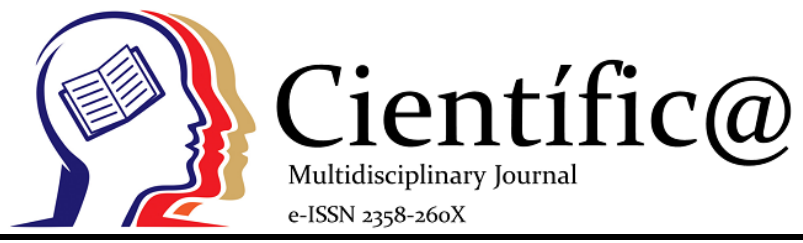

\title{
Balanço hídrico climatológico para o município de Rio Verde, Goiás
}

\author{
Water Balance Climatological To The County Of Rio Verde, Goiás \\ Ana Grabriela Borges Parreira ${ }^{1}$, Indiamara Marasca ${ }^{2}$, Antônio Jussiê da Silva Solino³, Gilmar \\ Oliveira Santos ${ }^{*}$ \\ ${ }^{1}$ Engenheira Ambiental pela Universidade de Rio Verde (UniRV). Email: anagabrielaparreira@icloud.com. \\ ${ }^{2}$ Professora Doutora na Universidade de Rio Verde (UniRV). Email: marasca@unirv.edu.br. \\ ${ }^{3}$ Professor Doutor na Universidade de Rio Verde (UniRV).Email: antoniosolino@unirv.edu.br. \\ 4*Professor Doutor na Universidade de Rio Verde (UniRV). Email: gilmar@unirv.edu.br. Telefone: (64) 3611-2291.
}

Info

Recebido: 16/04/2019

Publicado: $31 / 05 / 2019$

DOI: 10.29247/2358-260X.2019v6i1.p26-33

ISSN: 2358-260X

\section{Palavras-Chave}

Deficiência hídrica, Gestão hídrica,

Planejamento hídrico.

Keywords:

Water Deficiency, Water Management, Water Planning.

\section{Resumo}

O balanço hídrico é o resultado da quantidade de água que entra e sai de uma determinada camada do solo em um determinado intervalo de tempo, onde se caracteriza os períodos secos e úmidos de um local definido, enquadrando-se como ferramenta para o planejamento agrícola e ambiental. Esse trabalho teve como objetivo determinar o balanço hídrico climatológico (BHC) na cidade de Rio Verde, GO, no período de janeiro de 2012 a junho de 2015. O BHCN foi desenvolvido pelo método de Thornthwaite e Mather. Utilizou-se a capacidade de água disponível de $100 \mathrm{~mm}$. A precipitação anual é de $1.567 \mathrm{~mm}$, e evapotranspiração potencial anual foi de $1.430 \mathrm{~mm}$. 0 município apresentou tendência climática de seis meses de deficiência hídrica (maio a outubro) e seis meses de excedente hídrico (novembro a abril), totalizando 441 e $578 \mathrm{~mm}$, respectivamente. Para o manejo de culturas de sequeiro na região é necessário o uso de sistemas de irrigação para suprir a demanda hídrica, principalmente nos período de menor disponibilidade e maior demanda, consequentemente, sabendo o quanto e quando irrigar, além do uso racional da água.

\footnotetext{
Abstract

The water balance is the result of the amount of water that enters and exits a given layer of soil in a given time interval, which characterized the dry periods and wet a place defined, as part as a tool for the agricultural planning and environmental. This study aimed to determine the hydric balance climatological (BHC) in the city of Rio Verde, GO in the period from 2012 to 2015. The BHCN was developed by the method of Thornthwaite and Mather. Was used the water capacity available to 100 $\mathrm{mm}$. The annual precipitation is $1,567 \mathrm{~mm}$, and potential evapotranspiration was of $1,430 \mathrm{~mm}$. The municipality presented a trend climate of six months of water deficiency (May to October) and six months of water excess (November to April), totaling 441 and $578 \mathrm{~mm}$, respectively. For the management of arable land in the region the use of irrigation systems is needed to meet the demand for water, especially in the period of lower availability and higher demand, therefore, to know when and how much to irrigate, beyond the rational use of water.
} 


\section{INTRODUÇÃO}

O balanço hídrico climatológico desenvolvido por Thornthwaite e Mather (1955) é um instrumento agrometeorológico útil e prático para caracterizar a umidade do solo (Sentelhas e Angelocci, 2009). Este é considerado a primeira avaliação de água no solo em uma região, onde se contabiliza a entrada de saída de água do solo, propiciando em caracterizar os períodos secos (deficiência hídrica) e úmidos (excedente hídrico) de uma determinada região (Reichardt, 1990), podendo auxiliar na criação de uma área de zoneamento agrícola para diversas culturas (Barreto et al., 2009).

Segundo Thornthwaite e Mather (1955), o balanço hídrico climático conta com variáveis para sua importante realização, sendo elas: a precipitação total $(\mathrm{P})$, a evapotranspiração potencial (ETP) de cada período, e a capacidade de armazenamento máximo do solo (CAD Capacidade de Água Disponível). Essas três informações básicas permite o balanço hídrico climático determinar a evapotranspiração real (ETR), a deficiência (DEF) ou o excedente hídrico (EXC) e o total de água retida no solo (ARM).

A contabilização de água no solo é dada pela entrada através da chuva, orvalho e ascensão capilar, sendo o primeiro, responsável por mais de 99\% e as saídas por evapotranspiração e drenagem profunda, sendo a evapotranspiração responsável por mais de $84 \%$ (Pereira et al., 2002).

O balanço hídrico auxilia na definição dos períodos mais prováveis para chuva, e o menos provável. Tem relacionado fatores como evapotranspiração, precipitação, e também o conhecimento da característica da planta (Cintra et al., 2000). A adoção de técnicas como o planejamento ambiental é fundamental, tanto sustentável como economicamente, podendo assim, manter a longo tempo melhores condições dos recursos hídricos, além de assegurar a satisfação em aumento de produtividade agrícola (Wutke et al., 2000).

Para a correta elaboração do balanço hídrico, é necessário, também, o conhecimento da gestão de recursos hídricos, que está diretamente ligada a gestão ambiental que é um processo de ações que interagem a fim de garantir a adequação de exploração de recursos naturais com base nos princípios das diretrizes acordados e definidos inicialmente (Lanna, 1999). Além do aspecto ambiental, o balanço hídrico propicia no meio agronômico através do manejo da irrigação.

O balanço hídrico facilita o acesso a informações que favorecem ao agricultor conhecer sobre o momento mais propício para executar as etapas de manejo da cultura, assim como a que mais se adequa a região, incluindo também a definição na aquisição dos sistemas de irrigação e no dimensionamento da lâmina usada no sistema.

No entanto, o balanço hídrico possibilitará uma rápida caracterização do balanço de água no solo da região de Rio Verde - GO, por servir ferramenta ao planejamento e gestão ambiental e para fins agrícolas, uma vez que a região passa por um longo período de deficiência hídrica, onde o uso dos recursos hídricos é uma necessidade para assegurar o desenvolvimento local. 
Assim, o propósito desse trabalho foi determinar o balanço hídrico climatológico para o município de Rio Verde, Goiás, Brasil, como ferramenta ao planejamento agrícola.

\section{MATERIAL E MÉTODOS}

\section{Localização e caracterização da área de estudo}

Este trabalho foi realizado no município de Rio Verde, Sudoeste do Estado de Goiás, com população estimada, segundo IBGE (2010), em 176,424 mil habitantes. A vegetação é constituída de cerrado e matas residuais (Prefeitura Municipal de Rio Verde, 2016). O solo é do tipo Latossolo Vermelho Escuro com texturas argilosa e arenoargilosa (IBGE, 2010), esse tipo de solo tem como característica alta permeabilidade de água.
A partir dos dados climatológicos da Estação Convencional de Rio Verde do Instituto Nacional de Meteorologia (INMET) operada pela Universidade de Rio Verde (UniRV). A Estação está localizada na Latitude: $-17,8^{\circ}$ e Longitude: $50,9^{\circ}$ e altitude de $774,62 \mathrm{~m}$.

\section{Determinação do balanço hídrico climatológico}

O balanço hídrico climatológico foi desenvolvido pelo método de Thornthwaite e Mather (1955), em um modelo apresentado por Pereira et al. (2002), para determinar o regime hídrico de um local (Figura 1), sem necessidade de medidas diretas das condições do solo.

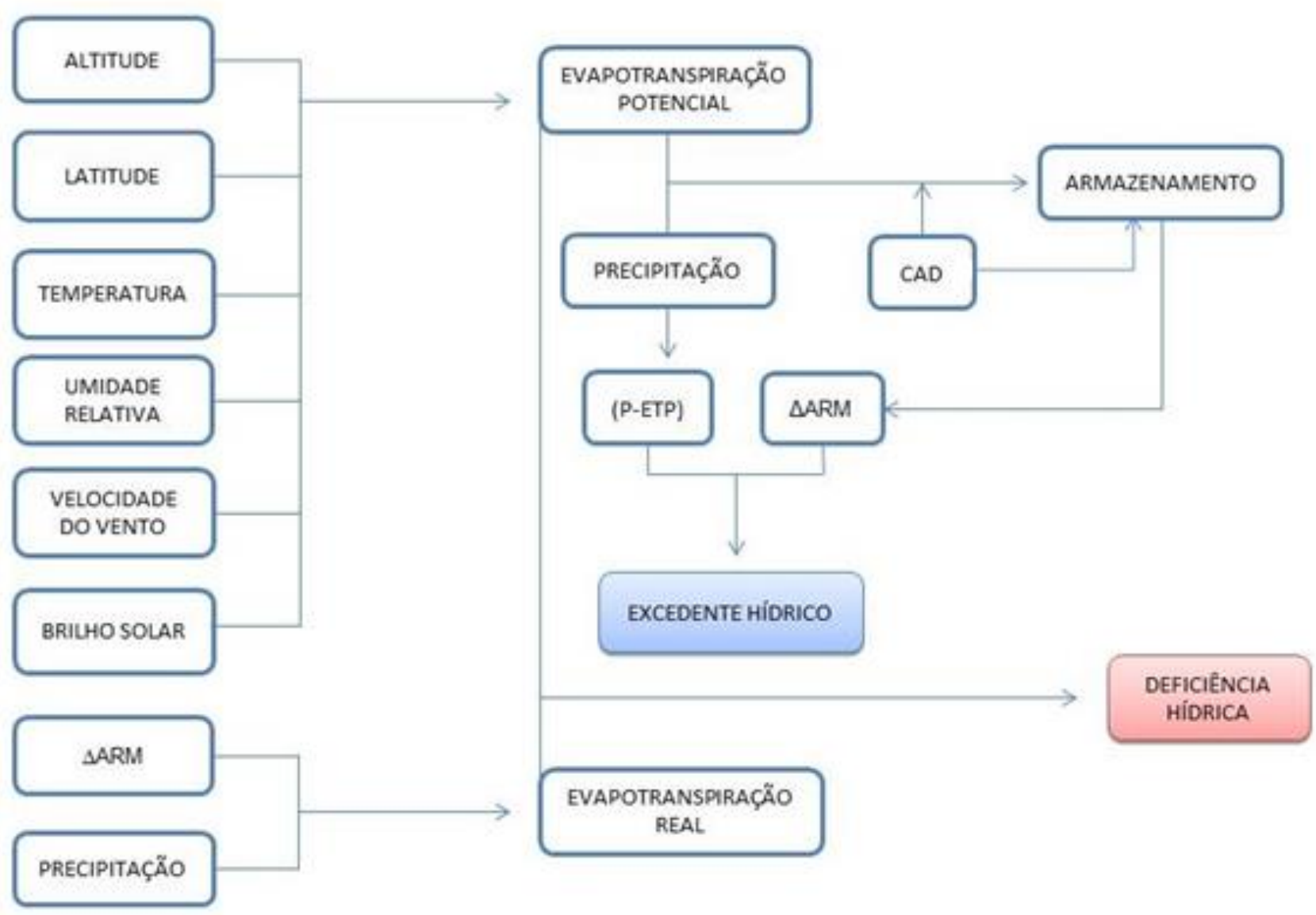

Figura1. Fluxograma do balanço hídrico climatológico. 
Para determinar o balanço hídrico foram utilizados dados de janeiro de 2012 a junho de 2015. Foram utilizados dados de precipitação disponibilizados pelo Instituto Nacional de Meteorologia (INMET). A evapotranspiração foi determinada pelo método Penman-Montheith com auxílio do software Sistema para Manejo da Agricultura Irrigada, SMAI v.2.0 (Mariano et al., 2011).

Adotou-se a capacidade de água disponível (CAD) média no Latossolo vermelho escuro de $100 \mathrm{~mm}$ (mm de água por $\mathrm{cm}$ de solo) conforme proposto por Araújo e Assad (2001) para a região sudoeste do Estado de Goiás.

\section{RESULTADOS E DISCUSSÃO}

O resultado do balanço hídrico climatológico para o município de Rio Verde está representado na Tabela1 e Figuras 2 e 3. A região foi caracterizada com precipitação média mensal de 130,6 $\mathrm{mm}$, com um total de $1.567 \mathrm{~mm}$ ao ano, com ênfase nos meses de novembro, fevereiro e março, que foram os meses com maior precipitação, concentrando $59 \%$ nesse período. O mês de agosto foi o mês mais crítico, não havendo precipitação. A ausência parcial de dados no mês de dezembro comprometeu a análise, representando parte da realidade na região.

Tabela 1. Balanço hídrico climatológico para o município de Rio Verde, Goiás, entre janeiro de 2012 a junho de 2015.

\begin{tabular}{|c|c|c|c|c|c|c|c|c|}
\hline \multirow{2}{*}{ Mês } & $\mathrm{P}$ & ETP & (P-ETP) & ARM & $\Delta \mathrm{ARM}$ & ETR & DEF & EXC \\
\hline & \multicolumn{8}{|c|}{$(\mathrm{mm})$} \\
\hline Jan & 165 & 135 & 30 & 100 & 0 & 135 & 0 & 30 \\
\hline Fev & 274 & 115 & 159 & 100 & 0 & 115 & 0 & 159 \\
\hline Mar & 352 & 117 & 235 & 100 & 0 & 117 & 0 & 235 \\
\hline Abr & 137 & 105 & 32 & 100 & 0 & 105 & 0 & 32 \\
\hline Mai & 50 & 99 & -49 & 61 & -39 & 89 & 10 & 0 \\
\hline Jun & 21 & 92 & -71 & 30 & -31 & 52 & 40 & 0 \\
\hline Jul & 17 & 107 & -90 & 12 & -18 & 35 & 72 & 0 \\
\hline Ago & 0 & 154 & -154 & 3 & -9 & 9 & 145 & 0 \\
\hline Set & 58 & 162 & -104 & 1 & -2 & 60 & 102 & 0 \\
\hline Out & 71 & 144 & -73 & 0 & -1 & 72 & 72 & 0 \\
\hline Nov & 298 & 129 & 169 & 100 & 100 & 129 & 0 & 69 \\
\hline Dez & 124 & 71 & 53 & 100 & 0 & 71 & 0 & 53 \\
\hline$\sum$ & 1.567 & 1.430 & 137 & - & 0 & 989 & 441 & 578 \\
\hline Média & 130,6 & 119,2 & 11,4 & - & - & 82,4 & 36,75 & 48,2 \\
\hline
\end{tabular}

Observação: $\mathrm{P}=$ Precipitação; ETP=Evapotranspiração potencial; ARM=Armazenamento de água no solo; $\Delta \mathrm{ARM}=$ Variação do armazenamento de água no solo; ETR=Evapotranspiração real; $\mathrm{DEF}=$ Deficiência hídrica e EXC=Excedente hídrico. 
O município possui evapotranspiração fevereiro e março os meses de maior destaque, potencial média mensal de 119,2 $\mathrm{mm}$, sendo o compreendendo $68,2 \%$ do excedente hídrico total. acumulado no ano de $1.430 \mathrm{~mm}$, com maiores

O período de deficiência hídrica foi de valores nos meses de agosto e setembro, com 154 maio a outubro, totalizando 6 meses, sendo o $\mathrm{mm}$ e $162 \mathrm{~mm}$, respectivamente, compreendendo $22,1 \%$ do total evapotranspirado. período mais crítico nos meses de agosto e setembro, compreendendo $56 \%$ da deficiência

Houve excedente hídrico no período de hídrica total. novembro a abril, totalizando $578 \mathrm{~mm}$, sendo

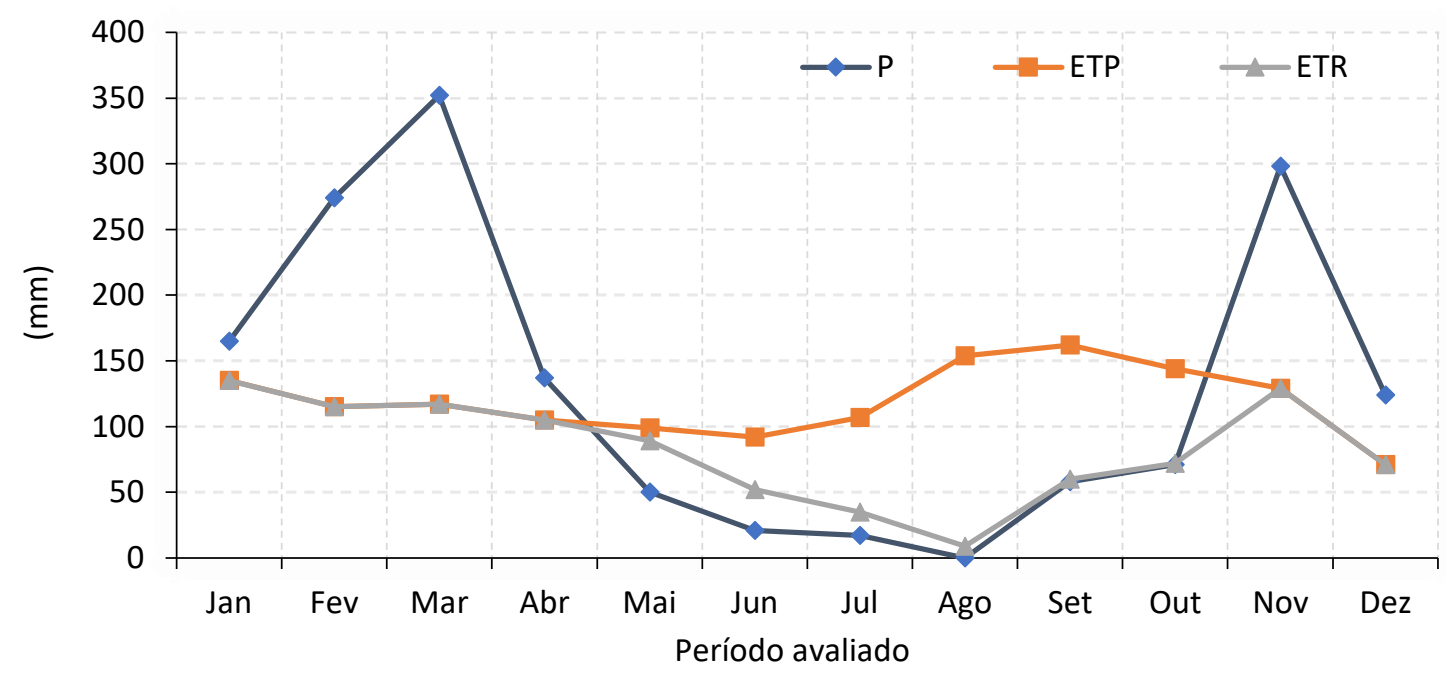

Figura 2. Representação do balanço hídrico climatológico para o município de Rio Verde, entre janeiro de 2012 a junho de 2015.

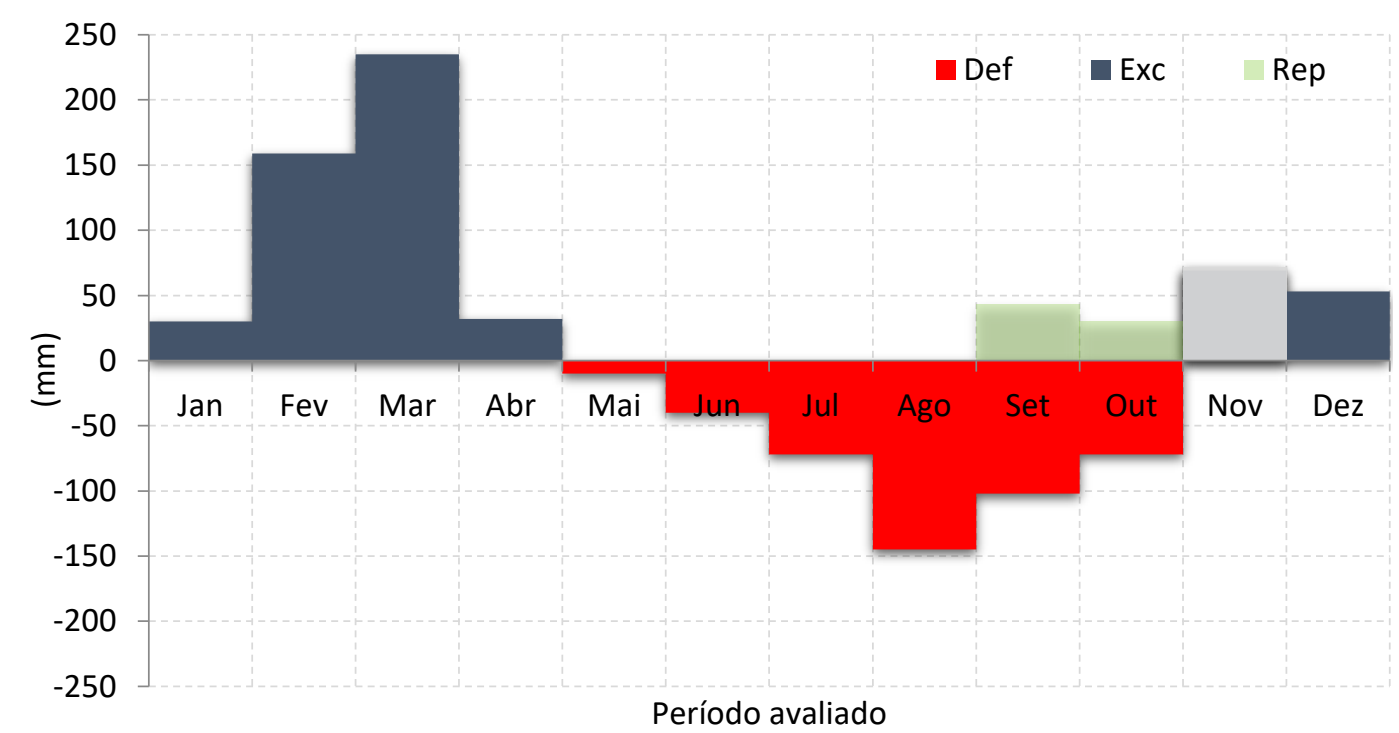

Figura 3. Extrato do balanço hídrico climatológico para o município de Rio Verde, entre janeiro de 2012 a junho de 2015. 
O período de reposição hídrica aconteceu no final do período de estiagem, representado pela deficiência hídrica, sendo de setembro até aproximadamente 18 de novembro. $\mathrm{O}$ mês de novembro foi um período de transição de água no solo, havendo reposição seguida de excedente de hídrico.

Quanto a designação das estações seca e chuvosa para a região de Rio Verde, resultados semelhantes foram obtidos pela Embrapa (s/d) avaliando a região de Rio Verde, denominando duas estações bem definidas para a região, sendo uma seca (maio a outubro) com deficiência hídrica e chuvosa (novembro a abril). Embora tenha se passado quase 30 anos, não houve mudanças significativas na característica climatológica na região, exceto quando ocorrem anos atípicos, com chuvas no período da seca e seca no período chuvoso.

A queda de precipitação em dezembro refletiu em menor excedente no mês de janeiro, devido aos dados incompletos disponibilizados pela estação meteorológica de Rio Verde. Porém, a mesma não prejudicou na caracterização climatológica da região.

Cruz et al. (2006) realizando o balanço hídrico na região de Jataí, Goiás, no período de julho de 2003 a novembro de 2005, obtiveram deficiência hídrica total de $108 \mathrm{~mm}$, sendo mais intensa nos meses de agosto e setembro e excedente hídrico de $905 \mathrm{~mm}$, concentrando no mês de dezembro.

Apesar do município de Rio Verde estar a cerca de $90 \mathrm{~km}$ de distância de Jataí, os fatores climáticos apresentam diferenças entre si, o que explica a importância de estudos locais. Em Rio Verde, a deficiência hídrica é precoce, começa em maio e segue até outubro com $441 \mathrm{~mm}$. Em Jataí, a deficiência hídrica começa um pouco depois, em junho e seu período de duração é menor, de junho a setembro (Cruz et al., 2006).

Houve 6 meses de deficiência hídrica em Rio Verde, ou seja, são 6 meses em que boa parte dos agricultores terão que utilizar sistemas de irrigação para conseguir suprir a demanda hídrica das culturas nesse período. Santos et al. (2010) fez o balanço hídrico climatológico para a região de Marinópolis - SP como ferramenta para o meio agropecuário, tendo como resultado 8 meses de deficiência hídrica e 3 meses de excedente hídrico com total de $179 \mathrm{~mm}$.

A baixa disponibilidade de água no solo influencia negativamente no crescimento e desenvolvimento da planta com redução na produtividade e produção de nutrientes, retardamento na distribuição e desenvolvimento do sistema radicular. (Santos et al., 2010).

É necessário o uso do sistema de irrigação na região de Rio Verde, contando que a região passa por 6 meses de deficiência hídrica, sendo 4 deles o período mais crítico. O sistema de irrigação garante a produtividade agrícola local, porém, os agricultores tem resistência ao definir quando e quanto se deve irrigar.

Quanto ao planejamento de plantio, o balanço hídrico climatológico disponibilizou dados de deficiência hídrica, quando o solo consequentemente fica menos produtivo, 
possibilitando a elaboração de tabelas ou modelos que levem em consideração as condições climáticas, além da cultura e seu estádio de desenvolvimento.

O reflorestamento ou demais plantios que necessitam do período chuvoso na região de Rio Verde, deve ser planejado para o período de novembro a abril, levando em consideração os anos atípicos, os quais as condições climáticas não são comuns, sendo necessário o balanço hídrico sequencial, que é usado para tomada de decisão.

Para a mesma região, de maio a outubro deve haver racionamento da água, concentrandose no mês de agosto, período que ocorre redução da precipitação. Sugere-se que faça políticas para conscientizar a população, como campanhas na área urbana e rural, reaproveitamento de água da chuva (período de excedente hídrico) e reutilizá-la no período seco. Essa ideia se aplica tanto a população urbana, quanto a população rural.

Brito e Santos (2015), reutilizando água da chuva durante um ano, estimaram que em uma residência de $70 \mathrm{~m}^{2}$ economiza-se $20 \mathrm{~m}^{3}$ ao ano. Se os produtores rurais da região aderissem à ideia, $\mathrm{o}$ que é essencial, em 100 ha, construindo um galpão de $2.000 \mathrm{~m}^{2}$ e criando um sistema de captação de água da chuva pelo telhado, deixaria de retirar do subsolo ou captação superficial de água de cerca de $1.143 \mathrm{~m}^{3}$ que devem ser armazenadas em um reservatório, que pode ser usada tanto para a irrigação, quanto para usos externos na casa ou até mesmo no galpão, que não seja para consumo, isso é uma medida socioambiental favorável ao meio ambiente e a economia do produtor.

\section{CONCLUSÃO}

Os resultados obtidos no presente trabalho propiciaram a uma tendência na caracterização climática em período secos e chuvosos da região de Rio Verde, favorecendo ao planejamento das atividades hidroagrícola e ambiental.

O município de Rio Verde apresentou tendência para duas estações bem definidas, sendo uma seca (maio a outubro) e uma chuvosa (novembro a abril) o que dificulta o manejo de culturas de sequeiro na região, sendo necessário o uso de sistemas de irrigação para suprir a demanda hídrica, principalmente nos período de menor disponibilidade hídrica e maior demanda, consequentemente, sabendo agora, quando e quanto irrigar, além do uso racional da água.

Para a implantação de um sistema de irrigação, é necessário um planejamento de recursos hídricos assegurando a qualidade da produção e segurança hídrica, visando melhorias no meio ambiente e favorecendo a economia do produtor rural.

\section{REFERÊNCIAS BIBLIOGRÁFICAS}

Araújo AG, Assad ML. Zoneamento pedoclimático por cultura a partir de levantamento de solos de baixa intensidade. Revista Brasileira de Ciência do Solo, 2001;25(1):103-111.

Barreto PN, Silva RBC, Souza WS. Análise do balanço hídrico durante eventos extremos para áreas de floresta tropical de terra firme da Amazônia Oriental. In: XVI Congresso Brasileiro de Agrometeorologia, 2009, Belo Horizonte. Anais... Belo Horizonte. CD. 
Brito $\mathrm{N}$ de, Santos GO. Proposta de reuso de água de telhado para casa de $70 \mathrm{~m}^{2}$ no município de Rio Verde - GO. Trabalho de Conclusão de Curso. Universidade de Rio Verde, 2015.

Cintra FLD, Libardi PL, Saad AM. Balanço hídrico no solo para porta-enxerto de citros em ecossistema de Tabuleiro Costeiro. Revista Brasileira de Engenharia Agrícola e Ambiental, 2000;4(1):23-28.

Cruz SP, Hernandez FBT, Vanzela LS. Balanço hídrico da região de Jataí - GO. CONIRD 2006 - XVI Congresso Nacional de Irrigação e Drenagem - Goiânia - 2006.

EMBRAPA - Monitoramento por satélite. Estudo realizado no período 1972-1987. s/d.

INMET. Instituto Nacional de Meteorologia. Ministério da Agricultura, Pecuária e Abastecimento. Disponível: http://www.inmet.gov.br/portal/. Acesso em: 5 jun 2015.

\section{INSTITUTO BRASILEIRO DE GEOGRAFIA} E ESTATÍSTICA. Censo demográfico $2010 . \quad$ Disponível: http://www.ibge.gov.br/home/. Acesso em: 5 - junho de 2015.

Lanna AE. Hidroeconomia. Academia Brasileira de Ciências - Águas Doces no Brasil - 1999.

Mariano JCQ, Santos GO, Feitosa DG, Hernandez FBT. Software para cálculo da evapotranspiração de referência diária pelo método de Penman-Monteith. In: CONIRD - Congresso Nacional de Irrigação e Drenagem, XXI, Anais... Petrolina: ABID, 20 a 25 de novembro de 2011, 2011. 6p. http://www.agr.feis.unesp.br/pdf/conird20 11_jean.pdf.

FINANCIAMENTO:
FAPESP, Processos 2009/52.467-4 e 2010/10.766-2.

Pereira AR, Angelocci LR, Sentelhas PC. Agrometeorologia: fundamentos e aplicações práticas. Guaíba (RS): Agropecuária, 2002. 478p.

Prefeitura Municipal de Rio Verde, 2016. Av. Presidente Vargas, 3215 - Vila Maria. Caixa Postal 34 - CEP 75901-970 - Rio Verde, Goiás - http://www.rioverde.go.gov.br.

Reichardt K. A água em sistemas agrícolas. Barueri (SP): Manole, 1990.

Santos GO, Hernandez FBT, Rossetti JC. Balanço hídrico como ferramenta ao planejamento agropecuário para a região de Marinópolis, noroeste do Estado de São Paulo. Revista Brasileira de Agricultura Irrigada, 2010;4(3):142-149.

Sentelhas PC, Angelocci LR. Balanço hídrico cilmatológico normal e sequencial, de cultura e para manejo de irrigação. In.: LCE 306 Meteorologia agrícola, 2009.

Thornthwaite CW, Mather JR. The water balance. Centerton, NJ: Drexel Institute of Technology - Laboratory of Climatology, 1955. 104p. (Publications in Climatology, v.8, n.1).

Wutke EB, Arruda FB, Fancelli AL, Pereira JCVNA0 Sakai E, Fujiwara M, Ambrosano GMB. Propriedades do solo e sistema radicular do feijoeiro irrigado em rotação de culturas. Revista Brasileira de Ciência do Solo, 2000;24(3):621-33. 